\title{
ANALISIS EFEKTIVITAS PENETAPAN JALUR TERKAIT DENGAN DWELLING TIME DI KANTOR PELAYANAN UTAMA BEA DAN CUKAI TIPE A TANJUNG PRIOK
}

\author{
Sunarmin, Noviandari Sari Utami, Wiwin Eka Yulianita \\ Email: surnamin3@gmail.com \\ Institut IImu Sosial dan Manajemen STIAMI
}

\section{ARTICLE INFO}

Keywords:

Path Determination,

Risk Managemen,

Dwelling Time

\section{ABSTRACT}

Path determination is one of the customs procedures regulated in Law No. 17 of 2006 on customs. Considering the Directorate General of Customs and Excise, especially Tanjung Priok Customs and Excise KPU is faced with two functions, namely service and supervision, the strategic step taken to answer the problems of both functions is by determining the path. This study aims to discuss the determination of paths associated with dwelling time. The main problem in this research is the extent of the effectiveness of the application of the determination of the path and its relation to the dwelling time which is the loading and unloading time of the container carried from the vessel to the container out of the port. This research is a qualitative descriptive research with data collection techniques in the form of interviews and data secondary. From the results of interviews and data processed by the authors then concluded that with the establishment of a system of determining the path at the Tanjung Priok Customs and Excise KPU has been quite effective in reducing the dwelling time in the port of Tanjung Priok.

\section{INTRODUCTION}

Pembangunan Nasional di suatu Negara diselenggarakan oleh pemerintah dengan dukungan sepenuhnya dari masyarakat. Peranan penerimaan pajak dalam Negeri menjadi sangatlah penting, karena diselenggarakan roda pemerintahan dan pembangunan nasional tidak mungkin tanpa hal ini. Sumber-sumber penerimaan dalam Negeri yaitu penerimaan sektor pajak dan bukan sektor pajak.

Perkembangan pembagian penerimaan negara pada APBN dalam empat tahun terakhir dapat dilihat di tabel I.1 berikut. :

Tabel I.1 : Penerimaan Negara pada APBN (dalam triliun rupiah)

\begin{tabular}{|c|c|c|c|c|c|c|c|c|}
\hline $\begin{array}{l}\text { Sumber } \\
\text { Penerimaan }\end{array}$ & \multicolumn{2}{|l|}{2014} & \multicolumn{2}{|l|}{2015} & \multicolumn{2}{|l|}{2016} & \multicolumn{2}{|l|}{2017} \\
\hline Perpajakan & 1246,1 & $76,20 \%$ & 1489,3 & $84,50 \%$ & 1539,2 & $86,10 \%$ & 1498,9 & $85,60 \%$ \\
\hline $\begin{array}{ll}\text { Bukan } & \text { Pajak } \\
\text { (PNBP) } & \end{array}$ & 386,9 & $23,70 \%$ & 269,1 & $15,30 \%$ & 245,1 & $13,70 \%$ & 250 & $14,30 \%$ \\
\hline Hibah & 2,3 & $0,10 \%$ & 3,3 & $0,20 \%$ & 2 & $0,20 \%$ & 1,4 & $0,10 \%$ \\
\hline Total & 1635,3 & $100 \%$ & $176170 \%$ & $100 \%$ & 1786,3 & $100 \%$ & 1750,3 & $100 \%$ \\
\hline
\end{tabular}

Sumber : situs www.kemenkeu.co.id

Berdasarkan tabel I.1 di atas, dapat dilihat bahwa penerimaan perpajakan masih menjadi penyumbang terbesar bagi pendapatan Negara pada Anggaran Pendapatan dan Belanja Negara (APBN). Pada 4 tahun terakhir, pendapatan Negara berasal dari penerimaan perpajakan selalu di atas $75 \%$ sehingga membuat sektor perpajakan menjadi obyek yang sangat vital bagi Negara. Di dalam APBN, penerimaan perpajakan diklasifikasikan ke dalam 2 (dua) sektor yaitu penerimaan pajak dalam Negeri dan penerimaan pajak Perdagangan Internasional. 
Salah satu pos penerimaan perpajakan khususnya yang berasal dari sektor pajak perdagangan Internasional adalah Bea Masuk. Menurut Undang-Undang Nomor 17 Tahun 2006 perubahan dari UndangUndang Nomor 10 Tahun 1995 tentang Kepabeanan, bea masuk didefinisikan sebagai "Pungutan Negara berdasarkan undang-undang ini yang dikenakan terhadap barang yang diimpor". Pelaksanaan pemungutan bea masuk dibebankan kepada Direktorat Jenderal Bea dan Cukai yang merupakan salah satu unit setingkat Eselon I dibawah Kementerian Keuangan.

Sebagai penghimpun penerimaan Negara, Direktorat Jenderal Bea dan Cukai dituntut untuk dapat memaksimalkan penerimaan bea masuk tiap tahunnya. Hal ini sesuai dengan tugas dan fungsi dari DJBC yaitu sebagai Trade Facilitator (memberi fasilitas perdagangan, diantaranya melaksanakan tugas titipan dari instansi lain), Industrial Assistance (Melindungi industri dalam Negeri dari persaingan tidak sehat dengan industri sejenis dari luar Negeri), Community Protector (Melindungi masyarakat dari masuknya barangbarang berbahaya) serta sebagai Revenue Collector (memungut pajak atas barang impor, barang ekspor serta cukai secara maksimal).

Kantor Pelayanan Utama Bea dan Cukai Tipe A Tanjung Priok merupakan salah satu kantor pelayanan bea dan cukai yang berada dibawah Direktorat Jenderal Bea dan Cukai. Sebagian besar kegiatan importasi melalui laut di Indonesia dilakukan melalui Pelabuhan Tanjung Priok. Oleh karena hal tersebut, KPU Bea dan Cukai Tipe A Tanjung Priok sebagai salah satu kantor pelayanan di DJBC dalam tugas dan fungsinya sebagai revenue collector yang setiap tahunnya diberikan beban target penerimaan yang cukup besar dalam bidang bea masuk dan bea keluar, cukai serta PDRI (Pajak Dalam Rangka Impor) lainnya.

Sesuai dengan tugas DJBC harus melakukan pemeriksaan barang secara selektif dengan metode sistem penjaluran pengeluaran barang impor. Prosedur penetapan jalur pengeluaran barang impor dalam rangka pemeriksaan barang secara selektif diterapkan DJCB ada empat jalur. Keempat jalur tersbut yaitu: 1. Jalur merah; 2. Jalur Kuning; 3. Jalur Hijau; 4. Jalur MITA. Pada importasi yang ditetapkan jalur merah, dilakukan pemeriksaan fisik barang dan penelitian dokumen impor kemudian diterbitkan SPPB (Surat Persetujuan Pengeluaran Barang), pada jalur kuning hanya dilakukan penelitian dokumen dan kemudian dapat diterbitkan SPPB tanpa dilakukan pemeriksaan fisik, sedangkan pada jalur hijau dapat terbit SPPB tanpa dilakukan pemeriksaan barang dan penelitian dokumen dilakukan setelahnya. Sedangka untuk jalur MITA memungkinkan proses pengeluaran barang impor tanpa dilakukan pemeriksaan fisik dan penelitian dokumen.

Sistem penjaluran ini tentunya membawa konsekuensi terhadap penerapan konsep self assessment yang memberikan kepercayaan penuh pada importir untuk memberitahukan barang impor melalui dokumen Pemberitahuan Impor Barang (PIB) dan menghitung serta membayar sendiri bea masuk dan pajak-pajak dalam rangka impor. Berikut data yang menggambarkan jumlah dokumen Pemberitahuan Impor Barang (PIB) dan penjaluran importasi pada KPU BC Tipe A Tanjung Priok pada tahun 2017:

Tabel I.2 : Jumlah Dokumen PIB dan Penjaluran Importasi Tahun 2017

\begin{tabular}{|l|l|l|}
\hline Jalur & Jumlah Dokumen PIB & \multicolumn{1}{|c|}{ Persentase (\%) } \\
\hline Merah & 34.679 & 6.26 \\
\hline Kuning & 52.018 & 9.39 \\
\hline Hijau & 381.082 & 68.79 \\
\hline Prioritas & 86.201 & 15.56 \\
\hline TOTAL & $\mathbf{5 5 3 . 9 8 0}$ & $\mathbf{1 0 0}$ \\
\hline
\end{tabular}

Sumber : Diolah oleh Peneliti dari KPU BC Tipe A Tanjung Priok

Dari data diatas, importasi yang mendapatkan jalur merah hanya sebesar 6.26\% atau sekitar 34.679 PIB dari total 553.980 PIB. KPU Bea dan Cukai Tipe A Tanjung Priok tidak mungkin melakukan pemeriksaan fisik terhadap semua importasi dikarenakan volume importasi yang sangat tinggi. Namun walaupun kecil tapi tidak boleh memungkiri bahwa jalur merah juga memiliki pengaruh yang cukup tinggi untuk kelancaran arus pada barang impor.

Proses pemeriksaan yang dilakukan dapat menjadi sebuah penghambat dalam menjaga kelancaran arus barang. Pada akhirnya DJBC hanya akan melakukan pemeriksaan fisik barang pada impor-impor yang memiliki tingkat risiko yang tinggi. Hal ini dilakukan agar pemeriksaan menjadi efektif dan mampu 
mendorong kelancaran arus barang. Penetapan tingkat risiko dilakukan berdasarkan Profil Importir dan Profil Komoditi. Profil importir adalah kumpulan elemen yang dapat mengindikasikan tingkat risiko importir, sedangkan profil komoditi adalah kumpulan elemen yang dapat mengindikasikan tingkat risiko komoditi.

Dalam hal hasil penelitian terhadap dokumen impor mengakibatkan kekurangan pembayaran Bea Masuk, Cukai, dan Pajak Dalam Rangka Impor (PDRI), maka Pejabat Bea dan Cukai menerbitkan Surat Penetapan Tarif dan/atau Nilai Pabean (SPTNP). Penetapan tarif dan/atau nilai pabean tertuang dalam SPTNP yang berfungsi sebagai penetapan Pejabat Bea dan Cukai, pemberitahuan, dan penagihan kepada importir. Berdasarkan pasal 16 UU no.17 Tahun 2006 tentang Kepabeanan, penetapan tarif dan nilai pabean dilakukan paling lama 30 hari sejak tanggal pendaftaran pemberitahuan pabean.

Table I.3 Table Jumlah SPTNP tahun 2015-2017

\begin{tabular}{|c|c|c|c|}
\hline SPTNP & 2015 & 2016 & 2017 \\
\hline $\begin{array}{ll}\text { SPTNP } & \text { yang } \\
\text { diterbitkan } & \end{array}$ & 17.404 & 18.095 & 29.508 \\
\hline $\begin{array}{l}\text { SPTNP } \\
\text { dibatalkan }\end{array}$ & 14 & 30 & 27 \\
\hline SPTNP yang dilunasi & 16.112 & 17.350 & 29.367 \\
\hline
\end{tabular}

Sumber : KPUBC Tipe A yang diolah oleh peneliti

Dari data hasil SPTNP yang ada pada tahun 2015-2017 menunjukkan bahwa bea cukai menerbitkan SPTNP dalam jumlah yang semakin meningkat, menandakan bahwa masih banyak pengguna jasa yang kurang diawasi oleh bea cukai.

Apabila tidak adanya pengawasan maka Negara akan menjadi rugi sebesar jumlah SPTNP setiap tahunnya. Sesuai dengan tugas dan fungsinya, bea cukai tetap harus melaksanakan pelayanan yang baik tanpa mengesampingkan sisi pengawasannya. Di dalam jalur importasi tetap dilakukan pengawasan dan khusus jalur merah dan jalur kuning yang dilakukan pemeriksaan fisik serta penelitian dokumen dapat mempengaruhi angka dwelling time.

Dwelling Time merupakan waktu rata-rata yang dibutuhkan oleh satu kontainer atau paket kiriman mulai dari bongkar sampai dengan keluar pelabuhan/bandara (gate-out). Semakin tinggi persentase pemeriksaan fisik maka dapat dipastikan semakin tinggi pula angka Dwelling Time yang dibutuhkan.

Arus penyelesaian importasi melalui prosedur kepabeanan di gudang impor terbagi menjadi tiga tahapan yaitu pre clearance, customs clearance, dan post clearance. Tahapan-tahapan tersebut tentu akan memunculkan Dwelling Time dalam setiap importasi barang kargo yang masuk. Berikut ini merupakan data dwelling time tahun 2017:

Tabel I.4 : Laporan Perhitungan Dwelling Time tahun 2017

\begin{tabular}{|c|c|c|c|c|c|c|}
\hline Jalur & Bulan & $\begin{array}{c}\text { Pre } \\
\text { Clereance }\end{array}$ & $\begin{array}{l}\text { Customs } \\
\text { Clereance }\end{array}$ & $\begin{array}{c}\text { Post } \\
\text { Clereance }\end{array}$ & $\begin{array}{c}\text { Dwelling } \\
\text { Time }\end{array}$ & $\begin{array}{c}\text { Rata- } \\
\text { Rata } \\
\text { DT }\end{array}$ \\
\hline \multirow{9}{*}{ MITA } & Januari & 1,409 & 0,000 & 1,384 & 2,793 & \multirow{9}{*}{2,647} \\
\hline & Februari & 1,100 & 0,002 & 1,294 & 2,397 & \\
\hline & Maret & 1,202 & 0,001 & 1,211 & 2,413 & \\
\hline & April & 1,366 & 0,003 & 1,339 & 2,708 & \\
\hline & Mei & 1,431 & 0,004 & 1,597 & 3,031 & \\
\hline & Juni & 1,419 & 0,000 & 1,404 & 2,823 & \\
\hline & Juli & 1,765 & 0,000 & 1,576 & 3,341 & \\
\hline & Agustus & 1,057 & 0,000 & 1,347 & 2,404 & \\
\hline & September & 1,246 & 0,001 & 1,250 & 2,497 & \\
\hline
\end{tabular}




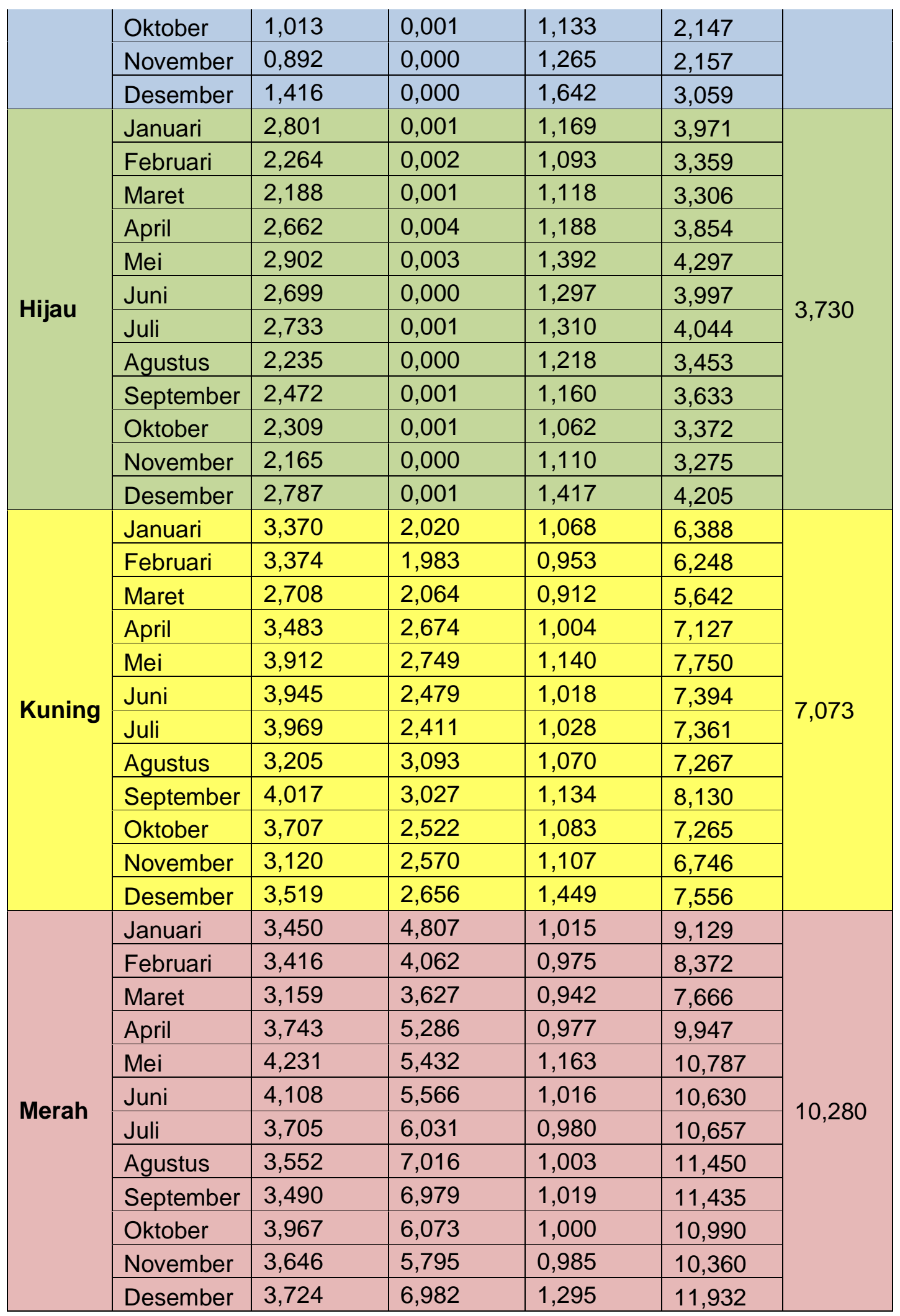

Sumber : KPU BC Tipe A Tanjung Priok yang diolah kembali oleh peneliti

Dari data di atas menunjukkan bahwa penyebab angka dwelling time masih tinggi terdapat di jalur merah dengan angka dwelling time sebesar 10,280 yang artinya lebih dari 10 hari. Sedangkan pemerintah menginginkan angka dwelling time sebesar 2,5 hari. Mungkin akan sangat sulit untuk menurunkan angka dwelling time menjadi kecil sesuai dengan keinginan pemerintah, namun DJCB terus berusaha menurunkan angka dwelling time menjadi lebih kecil. 
Dari data tersebut dapat terlihat bahwa rata-rata angka dwelling time dalam proses customs clearance khusus untuk jalur kuning dan merah masih cukup tinggi yaitu diantara 2 sampai dengan 6 hari. Ini menunjukkan bahwa masih di bawah harapan dari Pemerintah yang menetapkan dan menginginkan hanya 2,5 hari. Hal ini berdampak pada tidak efektif dari proses kelancaran arus barang dan mengakibatkan biaya high cost bagi perusahaan karena ada penumpukan barang.

Tulisan ini mencoba untuk menganalisis tentang penerapan Efektivitas Penetapan Jalur terkait dengan Dwelling Time di Kantor Pelayanan Utama Bea dan Cukai Tipe A Tanjung Priok.

\section{LITERATUR REVIEW}

Diskusi tentang Efektivitas Penetapan Jalur terkait dengan Dwelling Time di Kantor Pelayanan Utama Bea dan Cukai Tipe A Tanjung Priok. Menurut Krippendorff (1991: 15; dalam Retnoningsih, 2012: 35) analisis isi adalah suatu teknik untuk membuat inferensi-inferensi yang dapat ditiru (repicable) dan sahih, dengan memperhatikan konteksnya. Pengertian analisis menurut Harahap $(2009 ; 207)$ adalah memecahkan atau menguraikan sesuatu unit menjadi berbagai unit terkecil.

Kepabeanan menurut Purwito (2013:37), Kepabeanan adalah sesuatu yang berhubungan dengan pengawasan atas lalu litas barang yang masuk dan keluar daerah pabean dan pemungutan bea masuk. Dasar hukum kepabeanan di Indonesia tertutang dalam Undang-Undang Nomor 17 Tahun 2006 tentang Perubahan atas Undang-Undang Nomor 10 Tahun 1995 tentang Kepabeanan dan sebagaimana telah diubah dengan tentang Kepabeanan.

Menurut Maulidi (2017:01), Dwelling time adalah lamanya waktu seluruh proses mulai dari bongkar muat barang hingga barang keluar dari pelabuhan. Waktu berapa lama peti kemas (barang impor) ditimbun di Tempat Penimbunan Sementara (TPS) di pelabuhan sejak dibongkar dari kapal sampai dengan barang impor keluar dari TPS.

Menurut Yulianto (2016:01), Dwelling time merupakan sebuah proses yang dibutuhkan sejak barang/peti kemas turun dari kapal atau barang/peti kemas ditumpuk di lapangan penumpukan hingga barang/peti kemas keluar dari terminal/pelabuhan.

Bila dianalogikan, dwelling time adalah waktu tempuh. Artinya perjalanan barang impor dari bongkar hingga ke luar pelabuhan/bandara dinyatakan dalam satuan waktu, detik, menit, jam, hari dan seterusnya. Agar dapat diketahui apakah dwelling time bermasalah atau tidak, maka dibutuhkan "angka normal" sebagai acuan.

Semakin lama barang menumpuk di pelabuhan / bandara, semakin besar biaya yang ditanggung pelaku usaha. Dampaknya, harga jual barang akhir menjadi lebih mahal. Kinerja layanan bongkar muat di pelabuhan/bandara ditentukan banyak unit kerja. Seperti Bea Cukai, Karantina dan operasional swasta di pelabuhan/bandara. Semuanya secara bersama-sama berkongsi mempengaruhi kecepatan layanan pelabuhan/bandara. Setiap unit kerja ini bertanggung jawab terhadap instansinya masing-masing, yang biasanya memiliki pendataan dan model pengukuran berbeda.

Menurut Maulidi (2017:1) terdapat tiga tahap proses dwelling time yaitu Pre-Customs Clearance, Customs Clearance, dan Post Customs Clearance.

a. Pre Custome Clereance

Tahap sebelum, saat, dan sesudah pemberitahuan kedatangan sarana pengangkut laut / udara, penyerahan manifest yang dilakukan oleh agen pelayaran / penerbangan, kemudian dilanjutkan dengan penyampaian pemberitahuan impor ke Bea dan Cukai.

b. Customes Clereance

Tahap pemeriksaan yang terdiri dari pemeriksaan semua dokumen yang telah selesai dan pemeriksaan fisik barang kemudian terhadap barang tersebut dikeluarkan dari tempat penimbunan dan diterbitkan Surat Persetujuan Pengeluaran Barang (SPPB) oleh Bea dan Cukai.

c. Post Custome Clereance

Tahap setelah Surat Persetujuan Pengeluaran Barang (SPPB) diterbitkan oleh Bea dan Cukai sampai dengan proses pengeluaran barang dari Tempat Penimbunan Sementara (TPS). Di dalam ketiga proses 
tersebut, terdapat pemeriksaan karantina yang bila terkait barang berbahaya, memerlukan pemeriksaan laboratorium, sehingga bisa menambah dwelling time.

Menurut James L. Gibson (1996;38) yang dikutip oleh Harbani Pasolong (2012;51), mengatakan bahwa efektivitas adalah pencapaian sasaran dari upaya bersama. Derajat pencapaian sasaran menunjukkan derajat efektivitas. Sedangkan menurut Abdurahmat (2008: 7), efektivitas adalah pemanfaatan sumber daya, sarana dan prasarana dalam jumlah tertentu yang secara sadar ditetapkan sebelumnya untuk menghasilkan sejumlah pekerjaan tepat pada waktunya.

Sementara itu menurut Mahmudi dalam Aswar Annas (2017: 75) menjelaskan bahwa : "Efektivitas merupakan hubungan antara output dengan tujuan, maka semakin besar kontribusi output terhadap pencapaian tujuan, maka semakin efektif organisasi, program atau kegiatannya."

Sehubungan dengan hal-hal yang dikemukakan di atas, efektivitas suatu konsep yang dapat dipakai sebagai sarana untuk mengukur keberhasilan suatu organisasi yang dapat diwujudkan dengan memperhatikan faktor biaya, tenaga, waktu, sarana dan prasarana serta tetap memperhatikan resiko dan keadaan yang dihadapi.

Menurut Beni Pekei (2016:69-70) efektivitas adalah hasil guna kegiatan yang dilakukan pemerintah sedemikian rupa sehingga memungkinkan program dapat direncanakan dan dilaksanakan untuk mencapai tujuan dengan biaya serendah rendahnya dan waktu secepat cepatnya. Faktor penentu efisiensi dan efektivitas sebagai berikut :

a. Faktor Sumber Daya Manusia, seperti tenaga kerja, kemampuan kerja, maupun sumber daya fisik seperti peralatan kerja, tempat bekerja serta dana keuangan,

b. Faktor Struktur Organisasi yaitu susunan yang stabil dari jabatan-jabatan baik itu structural maupun fungsional,

c. Faktor Teknologi Pelaksanaan Pekerjaan,

d. Faktor Dukungan kepada aparatur dan pelaksanaannya baik pimpinan maupun masyarakat,

e. Faktor Pimpinan dalam arti kemampuan untuk mengkombinasikan keempat faktor tersebut kedalam suatu usaha yang berdaya guna dan berhasil guna untuk mencapai sasaran yang dimaksud.

\section{Efektivitas Penetapan Jalur Terkait dengan Dwelling Time di Kantor Pelayanan Utama Bea dan Cukai Tipe A Tanjung Priok}

\section{III.1. Faktor Sumber Daya Manusia}

Pada faktor ini, dapat dikatakan efektif jika suatu kebijakan dijalankan dengan tersedianya sarana dan prasarana yang memadai serta penggunaan sumber daya manusia secara optimal. Menurut Pelaksana Intelejen Penindakan dan Penyidikan bahwa sumber daya yang ada terkait dengan sumber daya manusia pada Kantor Pelayanan Utama Bea dan Cukai Tipe A Tanjung Priok belum memadai. Dikarenakan banyaknya jumlah importasi yang ditetapkan sebagai jalur merah yang mendapatkan respon Surat Pemberitahuan Jalur Merah (SPJK) yang mengharuskan barangnya diperiksa dan juga dilakukan penelitian dokumen oleh Pejabat Fungsional Pemeriksa Barang (PFPB) dan Pejabat Fungsional Pemeriksa Dokumen (PFPD). Ditambah lagi dengan importasi jalur kuning yang harus dilakukan penelitian dokumen sebelum diterbitkannya Surat Pemberitahuan Pengeluaran Barang (SPPB), yang menjadikan tugas dari PFPD semakin banyak.

Table III.1 : Table Jumlah PFPB\&PFPD dengan jumlah PIB 


\begin{tabular}{llll}
\hline Jalur & Jumlah PIB & PFPB & PFPD \\
\hline Merah & 34.679 & 91 & 101 \\
Kuning & 52.018 & - & \\
\hline
\end{tabular}

Sumber: KPUBC Tipe A Tanjung Priok yang diolah peneliti

Dari data tersebut dapat dilihat bahwa jumlah PFPB hanya 91 orang dan PFPD 101 orang, tentu tidak sebanding dengan jumlah PIB yang menunjukan pada jalur merah terdapat 34.679 yang harus dilakukan penelitian dokumen dan pemeriksaan fisik, dan jalur kuning sebanyak 52.018 yang harus dilakukan penelitian dokumen.

Selain itu, tidak sebandingnya jumlah PFPB dan PFPD yang ada dengan jumlah importasi disebabkan karena untuk penerimaan kepegawaian instansi pemerintah dibutuhkan waktu kurang lebih 1 kali dalam 1(satu) tahun. Karena perlu persiapan yang matang, dan seleksi yang ketat dilakukan, agar mendapatkan hasil yang maksimal.

Menurut Bapak Tri selaku Pelaksana Intelejen Penindakan dan Penyidikan (P2) di Bea dan Cukai Pusat Rawamangun mengatakan bahwa lamanya proses pemeriksaan fisik yang dilakukan juga terkait dengan sarana dan prasarana yang belum memadai, sarana dan prasarna yang jumlahnya masih terbatas disebabkan karena perlu waktu untuk mengajukan permintaan penambahan sarana dan prasarana agar memadai. Tentunya pengoptimalan sarana dan prasarana juga dibutuhkan, karena sarana dan prasarana dengan sumber daya manusia saling berkaitan. Dengan saranan dan prasarana yang belum memadai menjadikan Sumber Daya Manusia (SDM) harus berusaha semaksimal mungkin dengan tetap melakukan pengawasan tanpa mengesampingkan tugas pelayanan dari Bea Cukai.

Namun, sejauh ini untuk efisiensi terkait dengan jumlah Sumber Daya Manusia (SDM) di Kantor Pelayanan Utama Bea dan Cukai Tipe A Tanjung priok masih kurang efektif, karena walaupun kurangnya jumlah Sumber Daya Manusia (SDM) sudah bisa diatasi dengan mekanisme permintaan Bantuan Kerja Operasi (BKO) dengan cara meminta bantuan di bidang lain agar turut membantu pada bidang yang membutuhkan bantuan namun sifat BKO hanya sementara, jadi tetap dibutuhkan penambahan jumlah sumber daya manusia.

\section{III.2. Faktor Struktur Organisasi}

Pada faktor ini dikatakan efektif apabila struktur organisasi yang dijalankan terdiri dari jabatan-jabatan yang stabil, baik itu structural maupun fungsional menjalankan tugas dan fungsinya masing-masing secara maksimal. Sesuai dengan tugas dan fungsi bea cukai yaitu sebagai community protector yang berarti mengawasi setiap barang yang masuk ke dalam negeri.

Fungsi bea cukai sebagai community protector diterapkan pada sistem penetapan jalur. Dimana pada importasi jalur merah harus melalui pemeriksaan fisik yang dilakukan oleh PFPB dan penelitian dokumen yang dilakukan oleh PFPD sebelum diterbitkannya SPPB (Surat Persetujuan Pengeluaran Barang) oleh bea cukai.

Adapun tindakan dari bea cukai terhadap pengguna jasa yang kurang patuh terhadap aturan yang diberlakukan yaitu masih ada pengguna jasa yang dengan sengaja menahan barangnya di pelabuhan sedangkan SPPB sudah diterbitkan, padahal seharusnya saat SPPB sudah diiterbitkan maka pengguna jasa berkewajiban untuk mengeluarkan barangnya dari pelabuhan. Pengguna jasa yang bertindak seperti ini tentu berdampak pada pengguna jasa lainnya yang harus menunggu antrian lebih lama karena pelabuhan penuh berisikan pengguna jasa yang kurang patuh. Selain itu juga menyebabkan terjadinya kongesti di sekitar pelabuhan, maka tindakan yang dilakukan bea cukai hanya memberi himbauan kepada pihak TPS (Tempat Penimbunan Sementara) agar memerintahkan kepada pengguna jasa untuk dengan segera mengeluarkan barangnya dari TPS.

Table III.2 : Jumlah dokumen PIB dan jalur Importasi Tahun 2017 


\begin{tabular}{|c|c|c|}
\hline Jalur & Jumlah Dokumen PIB & Persentase (\%) \\
\hline Merah & 34.679 & 6.26 \\
\hline Kuning & 52.018 & 9.39 \\
\hline Hijau & 381.082 & 68.79 \\
\hline Prioritas & 86.201 & 15.56 \\
\hline TOTAL & $\mathbf{5 5 3 . 9 8 0}$ & $\mathbf{1 0 0}$ \\
\hline
\end{tabular}

Sumber : Diolah oleh Peneliti dari KPUBC Tipe A Tanjung Priok

Data di atas menunjukkan bahwa importasi yang berada di jalur MITA Prioritas sebanyak 86.201 PIB dengan persentase $15,56 \%$, jalur merah sebanyak 34.679 PIB dengan persentase hanya $6,26 \%$, jalur kuning sebanyak 52.018 PIB dengan persentase sebesar 9,39\%, dan jalur hijau sebanyak 381.082 dengan persentase tertinggi $68.79 \%$ yang menunjukkan bahwa banyak pengguna jasa yang ditetapkan sebagai jalur hijau, itu menunjukkan bahwa banyak pengguna jasa yang melakukan kegiatan importasi sesuai dengan aturan yang ditetapkan.

Table III.3 Hasil Pelunasan SPTNP Tahun 2015-2017

\begin{tabular}{|l|l|}
\hline Tahun & Jumlah \\
\hline 2015 & 921.886 .063 .256 \\
\hline 2016 & 788.122 .999 .304 \\
\hline 2017 & 1.244 .566 .599 .068 \\
\hline
\end{tabular}

Sumber : KPU BC Tipe A Tanjung Priok yang diolah peneliti

Dari hasil pelunasan SPTNP yang diterbitkan oleh bea cukai untuk pengguna jasa menunjukkan bahwa banyak pengguna jasa yang patuh dengan membayar pelunasan SPTNP dan jumlah tersebut semakin meningkat setiap tahunnya. Terkait dengan SPTNP juga dibutuhkan kerjasama oleh pihak bea cukai dan pengguna jasa. Dengan pengawasan yang dilakukan oleh bea cukai maka Negara menerima pemasukan pada tahun 2017 sebesar Rp. 1.244.566.599.068. jika tidak dilakukan pengawasan tentunya angka Rp. 1.244.566.599.068 menjadi kerugian bagi Negara.

Koordinasi yang dilakukan antara bea cukai dengan pengguna jasa sudah baik, tentu itu menjadikan faktor ini dapat dikatakan sudah cukup efektif.

\section{III.3. Faktor Teknologi Pelaksanaan Pekerjaan}

Pada faktor ini dikatakan efektif apabila dalam sistem yang dijalankan diterapkan secara adil, maksudnya yaitu untuk kepentingan publik tidak terabaikan. Menurut Client Coordinator Kantor Pelayanan Utama Bea dan Cukai Tipe A Tanjung Priok mengatakan bahwa penetapan jalur dijalankan dengan sistem, saat penggunja jasa menginput dokumen Pemberitahuan Impor Barang (PIB) maka saat itu akan mendapat respon penjaluran.

Dalam Undang-Undang Kepabeanan No 17 tahun 2006 dalam pasal 3 menyebutkan bahwa pemeriksaan pabean harus dilakukan secara selektif dan sesuai dengan PER 16/BC/2016 dalam pasal 4 ayat 3 menyebutkan bahwa penetapan jalur ditetapkan berdasarkan profil atas operator ekonomi (Importir, Perusahaan Pengurusan Jasa Kepabenanan, Pengangkut, Pengusaha Tempat Penimbunan Sementara dan pihak lainnya yang terkait dengan pergerakan barang impor), profil komoditi, pemberitahuan pabean, metode acak dan informasi intelejen. Menurut Koordinator Kepatuhan Internal Kantor Pelayanan Utama Bea dan Cukai Tipe A Tanjung Priok mengatakan semua importir saat pertama kali melakukan kegiatan impor tentu akan ditetapkan sebagai jalur merah dan mendapatkan respon SPJM, karena menurut pihak bead an cukai importasi pertama dianggap sebagai highrisk atau importir berisiko tinggi.

Namun seiring berjalan waktu importasi yang ditetapkan sebagai jalur merah bisa berubah menjadi jalur kuning atau bahkan tidak menutup kemungkinan mendapatkan jalur hijau, apabila importir selalu patuh 
terhadap aturan yang ada misalnya dengan menyampaikan dokumen sesuai dengan fisik barang. Berubahnya setiap respon penjaluran yang didapatkan pengguna jasa ketika melakukan kegiatan importasi barang tergantung dari pengguna jasa itu sendiri.

Menurut Minerva selaku pengguna jasa mengatakan bahwa menurutnya penetapan jalur belum berlaku adil, karena masih belum mengetahui cara bea cukai dalam menetapkan jalurnya. Sebenarnya itu yang diharapkan bea dan cukai, para pengguna jasa tidak bisa menebak indikator apa yang dijadikan sebagai alat ukur dalam menetapkan jalur. Karena apabila para pengguna jasa mengetahui, bisa terjadi kecurangan yang dilakukan agar bisa mendapatkan jalur hijau. Sesuai dengan Undang-Undang kepabeanan yang dijadikan indikator dalam menetapkan jalur hanya berdasarkan dari profil importir dan profil komoditi, selebihnya adalah sistem yang menentukan.

Dengan berbagai macam indikator yang disebutkan maka dalam faktor teknologi pelaksanaan pekerjaan menunjukkan bahwa penetapan jalur sudah efektif dalam menentukan jalur kepada pengguna jasa dan juga efektif. Karena jalur yang ditetapkan sudah sesuai berdasarkan undang-undang yang ada yaitu Undang-Undang Nomor 17 tahun 2006 tentang kepabeanan.

\section{III.4. Faktor Dukungan kepada Aparatur dan Pelaksanaannya}

Dalam faktor ini dapat dikatakan efektif apabila dalam suatu kebijakan dibuat berdasarkan aturan dan harus didukung dengan aparatur yang membuat kebijakan dan tidak terlepas dari pelaksananya antara aparatur dan pelaksana tentu dibutuhkan kerjsama yang baik, agar suatu kebijakan dapat berjalan sesuai dengan tujuan.

Pihak-pihak yang terkait dalam proses importasi tida sedikit, menurut coordinator kepatuhan internal bea dan cukai tanjung priok mengatakan bahwa pihak yang terkait seperti pihak dari pelayaran, intansi perizinan yang terkait dengan barang yang diimportasi, pihak TPS untuk penimbunan sementara container, PPJK yang dikuasakan oleh pengguna jasa untuk mengurus importasi, dan masih ada petugas pemeriksaan pada saat pemeriksaan barang dan penelitian dokumen, dari semua pihak-pihak tersebut dibutuhkan kerjasama yang baik agar tujuan dapat tercapai.

Atas kerjasama yang dilakukan dari berbagai pihak yang terlibat, maka akan membawa dampak kepada pengguna jasa. Agar faktor ini dapat efektif maka dibutuhkan kerjasama dari pengguna jasa, dari sikap-sikap pengguna jasa yang patuh akan aturan yang ada tentu sangat membantu proses kelancaran arus barang cepat selesai.

Table III.4 : Table Jumlah Dokumen PIB tahun 2015-2017

\begin{tabular}{|l|c|c|c|}
\hline \multirow{2}{*}{$\begin{array}{c}\text { Penetapan } \\
\text { Jalur }\end{array}$} & \multicolumn{3}{|c|}{ Jumlah Dokumen PIB } \\
\cline { 2 - 4 } & $\mathbf{2 0 1 5}$ & $\mathbf{2 0 1 6}$ & $\mathbf{2 0 1 7}$ \\
\hline Jalur Merah & 38.301 & 36.143 & 55.958 \\
\hline Jalur Kuning & 101.850 & 89.306 & 72.769 \\
\hline Jalur Hijau & 258.806 & 323.074 & 367.993 \\
\hline Jalur MITA & 106.025 & 40.850 & 113.163 \\
\hline TOTAL & $\mathbf{5 0 4 . 4 8 2}$ & $\mathbf{5 5 7 . 6 8 6}$ & $\mathbf{6 0 9 . 8 8 3}$ \\
\hline
\end{tabular}

Sumber : KPUBC Tipe A Tanjung Priok

Dari tingkat kepatuhan pengguna jasa yang menunjukkan sudah efektif, terlihat dari jumlah jalur hijau yang lebih unggul dan terus meningkat setiap tahunnya dibanding dengan jalur merah, jalur kuning dan jalur MITA menandakan bahwa pengguna jasa juga ikut mendukung proses importasi dengan sistem penetapan jalur yang dibuat oleh bea cukai.

Dengan tingginya jalur hijau namun tidak membuat bea cukai lalai dalam sisi pengawasannya. Bea dan cukai tetap melakukan pengawasan sesuai dengan tugas dan fungsinya. Pengawasan yang dilakukan bea cukai dapat diilhat dari jumlah SPTNP yang diterbitkan oleh bea dan cukai, SPTNP diterbitkan karena pengguna jasa dicurigai melakukan kecurangan atas dokuemn yang seharusnya.

Table III.5 : Table Jumlah SPTNP Tahun 2015-2017 


\begin{tabular}{|l|r|r|r|}
\hline \multicolumn{1}{|c|}{ SPTNP } & $\mathbf{2 0 1 5}$ & $\mathbf{2 0 1 6}$ & \multicolumn{1}{c|}{$\mathbf{2 0 1 7}$} \\
\hline SPTNP yang diterbitkan & 17.404 & 18.095 & 29.508 \\
\hline SPTNP yang dibatalkan & 14 & 30 & 27 \\
\hline SPTNP yang dilunasi & 16.112 & 17.350 & 29.367 \\
\hline
\end{tabular}

Sumber : KPUBC Tipe A yang diolah oleh peneliti

Dari data tersebut dapat diihat tingkat efektivitas penetapan jalur

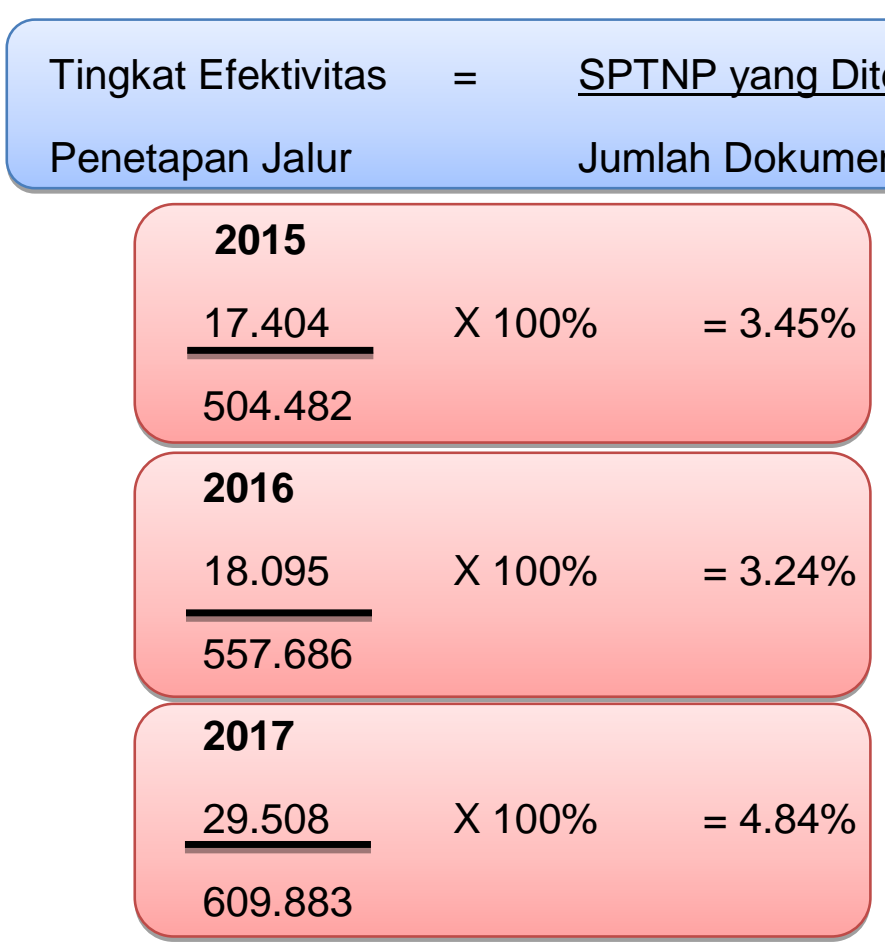

Dari persentase tersebut tingkat efektivitas penetapan jalur terhadap SPTNP yang diterbitkan semakin naik menandakan bahwa pengawasan yang dilakukan oleh bea cukai dalam menindaklanjuti pengguna jasa yang kurang patuh sudah teratasi. Dan tentunya diperlukan koordinasi antar sesama pihak lainnya agar berkurangnya SPTNP yang diterbitkan. Dengan data yang ada maka dinyatakan dalam faktor ini dapat dikatakan sudah efektif.

\section{III.5. Faktor Pimpinan}

Pada faktor ini, dikatakan efektif apabila suatu kebijakan mampu uuntuk mengkombinasikan keempat faktor ke dalam suatu usaha yang berdaya guna dan berhasil guna untuk mencapai. Dalam membuat sistem penetapan jalur, tentunya pasti bertujuan. Menurut Client Coordinator Bea Cukai Rawamangun mengatakan bahwa Penetapan jalur merupakan bagian dari manajemen risiko, ada 2 (dua) tugas bea cukai yang saling berkontradiksi yaitu tugas terkait pelayanan kepabeanan cukai ekspor impor dan pengawasan atas peredaran impor barang illegal. Artinya bea cukai dituntut untuk menyeimbangkan keduanya, agar pelayanan berjalan dengan cepat tetapi tidak mengesampingkan sisi pengawasannya. 


\begin{tabular}{|l|l|l|l|}
\hline Tahun & Target & Realisasi & \% \\
\hline 2015 & 18.194 & 14.904 & 81.93 \\
\hline 2016 & 16.352 & 15.118 & 92.45 \\
\hline 2017 & 15.513 & 16.937 & 109.18 \\
\hline
\end{tabular}

Sumber : KPU BC Tipe A Tanjung Priok

Dalam target penerimaan pabean tahun 2015, 2016 dan 2017 dapat dilihat bahwa realisasi setiap tahunnya pencapaian semakin mencapai target bahkan pada tahun 2017 sudah melebihi target sebesar 109.18\% dengan target sebesar 15.513 dan realisasi sebesar 16.937. maka pada tahun 2017 dikatakan sudah cukup efektif.

Sedangkan dalam penetapan jalur yang bertujuan untuk mempercepat proses keberlangsungan kelancaran arus barang yang terjadi di pelabuhan. Selain itu, penetapan jalur ditujukan untuk efektivitas pemeriksaan yang jelas, karena dengan diperiksa tentu akan mengurangi risiko masuknya barang-barang terlarang ke Indonesia. Dan juga mengukur tingkat kepatuhan importir dalam menjalani aturan yang ada dan penggunaan secara optimal terkait sarana dan prasarana yang tersedia dengan keterbatasan sumber daya manusia.

Dilihat dari tujuan-tujuan dibuatnya sistem penetapan jalur tentunya penetapan jalur mempengaruhi tinggi rendahnya angka dwelling time di pelabuhan. Dengan dibuatnya sistem penetapan jalur, maka bagi pengguna jasa yang mendapat respon SPJM (Surat Pemberitahuan Jalur Merah) harus dilakukan pemeriksaan barang dan juga penelitian dokumen dan untuk respon SPJK (Surat Pemberitahuan Jalur Kuning) yang hanya dilakukan penelitian dokumen sebelum diterbitkannya SPPB (Surat Pemberitahuan Pengeluaran Barang).

Table IV. 11 : Table customs clereance 2017

\begin{tabular}{|c|c|c|c|}
\hline Jalur & Bulan & Customs Clereance & Rata-Rata DT \\
\hline \multirow{12}{*}{ MITA } & Januari & 0,000 & \multirow{12}{*}{0,00121736} \\
\hline & Februari & 0,002 & \\
\hline & Maret & 0,001 & \\
\hline & April & 0,003 & \\
\hline & Mei & 0,004 & \\
\hline & Juni & 0,000 & \\
\hline & Juli & 0,000 & \\
\hline & Agustus & 0,000 & \\
\hline & September & 0,001 & \\
\hline & Oktober & 0,001 & \\
\hline & November & 0,000 & \\
\hline & Desember & 0,000 & \\
\hline \multirow{2}{*}{ Hijau } & Januari & 0,001 & \multirow{2}{*}{0,001254975} \\
\hline & Februari & 0,002 & \\
\hline
\end{tabular}




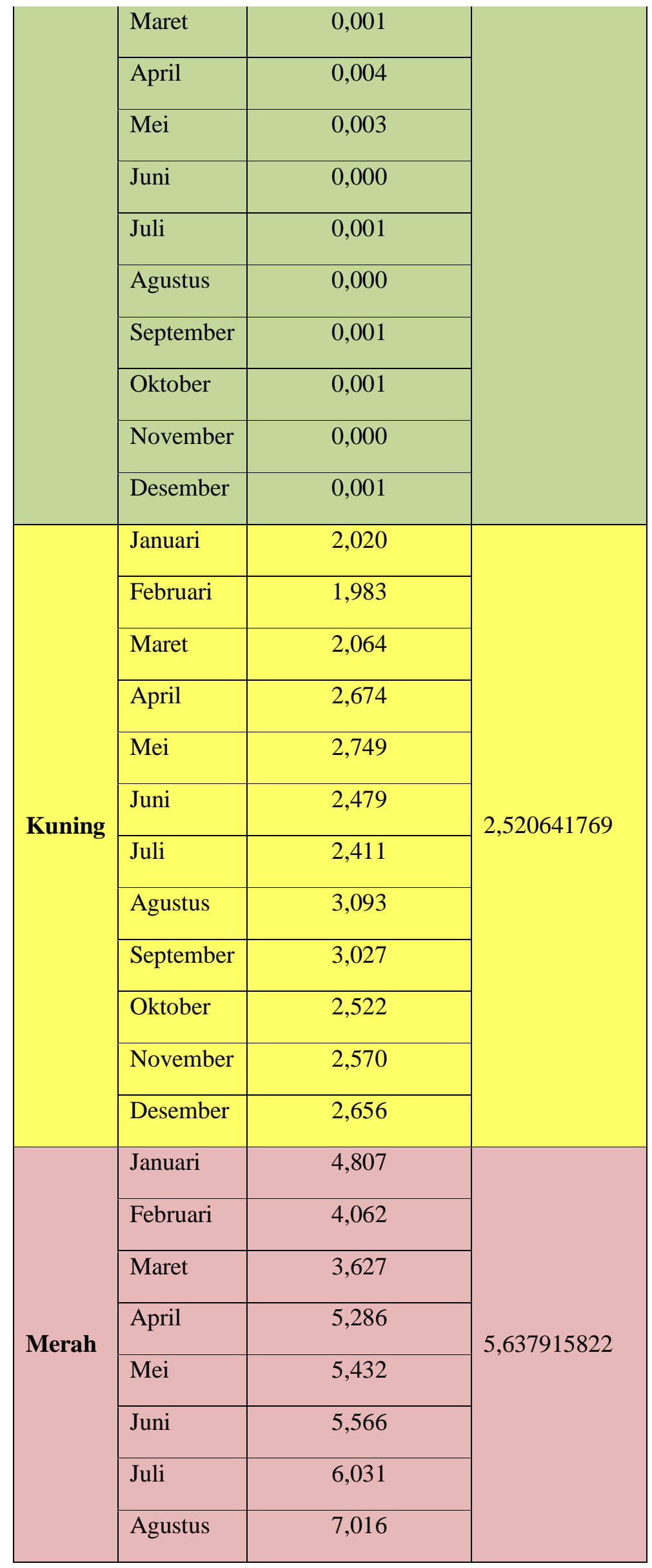




\begin{tabular}{|c|c|}
\hline September & 6,979 \\
\hline Oktober & 6,073 \\
\hline November & 5,795 \\
\hline Desember & 6,982 \\
\hline
\end{tabular}

Sumber : KPUBC Tipe A Tanjung Priok yang diolah peneliti

Dari data di atas menunjukkan bahwa pada jalur MITA dan Hijau angka rata-rata dwelling time masih menunjukkan sudah di bawah 3 hari. Namun pada jalur Kuning dan Merah melebihi angka 3 hari.

Berdasarkan tujuan yang ada dan hasil yang diperoleh maka dapat dikatakan efektif apabila mencapai tujuan dwelling time dalam penyelesaian customs clearance yaitu 1 (satu) hari atau di bawah 1 (satu) hari. Dari 4 (empat) jalur yang ada didapati 2 (dua) jalur yaitu jalur prioritas dan jalur hijau sudah efektif karena di bawah 1 (satu) hari sedangkan 2 (dua) jalur lainnya yaitu kuning dan merah belum efektif dikarenakan masih di atas 1 (satu) hari.

\section{CONCLUSIONS}

Tingkat Efektivitas penetapan jalur terkait dengan dwelling time di Kantor Pelayanan Utama Bea dan Cukai Tipe A Tanjung Priok dilihat dari 5 (lima) faktor, yaitu faktor sumber daya manusia, faktor struktur organisasi, faktor teknlogi pelaksanaan pekerjaan, faktor dukungan kepada aparatur dan pelaksanaannya serta faktor pimpinan. Dari ke lima faktor tersebut yang dikatakan belum efektif yaitu terkait dengan faktor sumber daya manusia karena jumlah sumber daya manusia yang belum sebanding dengan jumlah PFPB dan PFPD di Kantor Pelayanan Utama Bea dan Cukai Tipe A Tanjung Priok. Kemudian faktor struktur organisasi yang ternyata masih kurangnya kesadaran pengguna jasa akan peraturan yang ada yang dibuat oleh Bea Cukai. Terkakhir yang terkait dengan faktor pimpinan pada tahapan customs clereance. Dari 4 (empat) jalur yang ada, didapati 2 (dua) jalur yatu jalur prioritas dan jalur hijau sudah efektif karena angka dwelling time menunjukkan di bawah 1 (hari) sedangkan 2 (dua) jalur lainnya yaitu jalur kuning dan jalur merah belum efektif karena angka dwelling time menunjukkan masih lebih dari 1 hari.

\section{REFERENCES}

Abdurahmat. 2008. Efektivitas Organisasi Edisi Pertama.Jakarta : Airlangga

Annas, Aswar. 2017. Interaksi Pengambilan Keputusan Dan Evaluasi Kebijakan. Makassar: Celebes Media Perkasa

Harahap, Sofyan Syafri. 2009. Analisis Kritis Atas Laporan Keuangan. Jakarta: Raja Grafindo Persada.

Pasolong, Harbani Pasolong 2012. "Metode Penelitian Administrasi Publik" Bandung : Alfabeta

Pekei, Beni 2016 “Konsep dan Analisis Efektivitas Pengelolaan Keuangan Daerah di Era Ekonomi” Jakarta : Taushia

Purwito M, Ali. 2013. “Kepabeanan Indonesia.” Tangerang Selatan: Jelaja Nusa. 